\title{
Stroke units: The implementation of a complex intervention
}

\author{
Kilbride, C., Meyer, J., Flatley, M. \& Perry, L.
}

\begin{abstract}
This article reports on selected findings from an action research study that looked at the lessons learnt from setting up a new in-patient stroke service in a London teaching hospital. Key participants in the design and evaluation of this 2-year study included members of the multi-professional stroke team and support staff within the unit, the hospital management team and representatives of patients and carers. Mixed methods (focus groups, indepth interviews, audits, documentary analysis, participant observation field notes) were used to generate data. Findings demonstrated positive change overtime with four main themes emerging from the process: building a team; developing practice-based knowledge and skills in stroke; valuing the central role of the nurse in stroke care; and creating an organisational climate for supporting change. The interplay of these non-linear, but interrelated factors is supported by complexity theory, which includes exploration of how the sum of a whole can be more than its constituent parts. Findings are likely to be of interest to practitioners, managers and policy makers interested in supporting change in a learning organisation.
\end{abstract}

Keywords: action research; case study; process; stroke; stroke unit care; teamwork

\section{Introduction}

Stroke is defined as a focal or global neurological impairment of sudden onset lasting longer than 24 hours or leading to death, and of presumed vascular origin (World Health Organisation, 1978). It is the third leading cause of death in the world and the leading cause of severe disability in the United Kingdom (UK) (Hankey, 1999; European Stroke Initiative Executive Committee, 2003). Stroke units are said to be the single most effective treatment for stroke with effects of their input being both long lasting and reducing the odds of death by almost $20 \%$ and of death and dependency by $30 \%$ (Rudd \& Matchar, 2004; Stroke Unit Trialists' Collaboration [SUTC],2004). Yet, the establishment of stroke units has been limited in the UK and many stroke patients receive the majority of their care elsewhere, i.e. general medical wards (Rudd et al, 2001; Rudd \& Matchar, 2004). Indeed, the first National Sentinel Stroke Audit, (Clinical Effectiveness \& Evaluation Unit [CEEU], 1998) showed that only between 10 and $27 \%$ of stroke patients were able to spend more than $50 \%$ of their time in a specialist stroke unit (Rudd et al, 2001) and subsequent audits in 1999, 2002 and 2004 demonstrate that this remains a problem (CEEU, 2004). The lack of dedicated stroke beds is thought to be a major contributor to the 4500 avoidable deaths and 7000 institutional placements that occur every year in the UK (Ebrahim \& Redfern, 1999). The reasons for the lack of dedicated stroke beds may be linked to ageist practice, but equally, whilst policies recommend the establishment of stroke units (e.g. National Service Framework for Older People, Department of Health, 2001a), they do not give advice on how best to establish such a service. This is the focus of the study reported here.

A stroke unit is a system of complex in-patient care delivered by a coordinated specialist multidisciplinary team with expertise in stroke and rehabilitation (Langhorne \& Pollock, 2002). Key characteristics include:

- consultant physician with responsibility for stroke;

- staff with specialist expertise in stroke and rehabilitation;

- coordinated multidisciplinary team that meets at least once a week for the interchange of information about individual patients;

- continuing education programmes for staff;

- provision of information to patients and carers about stroke; 
- formal links with patient and carer organisations (SUTC 1997, 2004).

Interestingly, survival rates for stroke patients cared for in geographically distinct stroke units are better than for those stroke patients managed by a specialist peripatetic stroke team (Kalra et al, 2000). This suggests that a stroke unit is more than just specialist individuals working together (Langhorne, 1995). However previous outcome-driven quantitative studies have been unable to clarify the processes involved in delivering good care. For instance, the randomised controlled trial carried out by Indredavik et al (1999) showed that stroke unit care achieved recommended higher levels of intravenous saline hydration, early mobilisation (within 24 hours), oxygen therapy, better use of paracetemol and heparin, together with the prescription of aspirin and insulin within 24 hours. These factors were seen to be fundamental in achieving successful outcomes for patients yet it was not possible from the design of the study, to actually determine how this was achieved in practice. This indicates a need for more process-orientated studies that are practice based and action orientated.

\section{Context of the Study}

The stroke service, which was comprised of a 12-bed acute stroke unit (ASU) and a 16-bed rehabilitation stroke unit (RSU), was set up in November 2000. It was based within a large acute hospital trust (1200+ beds, 4000+staff), across two sites (less than a $1 \mathrm{~km}$ apart), but operated as one unit. The setting up of the stroke unit was the management's response to the hospital's poor results in the National Sentinel Stroke Audits (CEEU, 1998, 1999). The audit results highlighted that despite being a teaching hospital with many national and international specialities, including neurosciences, stroke care was at best fragmented and uncoordinated, with patients being on any one of 18 wards and without specialist input from appropriate healthcare staff. These findings confirmed what clinical staff had been saying for a long time, and represented a coming together of the practitioner and management accounts. A working party was set up and successfully secured funding from the hospital's Special Trustees to undertake an action research study.

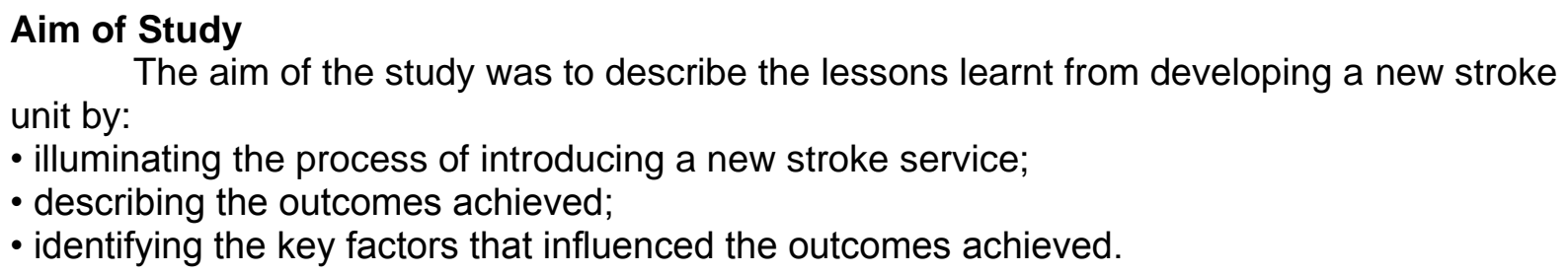

The aim of the study was to describe the lessons learnt from developing a new stroke

- illuminating the process of introducing a new stroke service;

- describing the outcomes achieved;

- identifying the key factors that influenced the outcomes achieved.

\section{Methodological Approach}

Action research was purposively selected as the methodology of choice for this collaborative inquiry into stroke care with the impetus for the project coming directly from a self-established group of multi-professional staff that wanted to improve intervention for stroke in the hospital. Some members of this group later went on to become co-researchers on the project.

Action research comes in many different forms. It has evolved over time and from a wide range of fields including organisational work (Coghlan \& Brannick, 2005), education (Carr \& Kemmis, 1986), community development projects (Reason \& Bradbury, 2001) and health (Meyer, 2000). Hart \& Bond (1995) developed a typology of action research to represent four basic types: experimental; organisational; professionalising and empowering. Broadly, this action research study can best be described as 'professionalising', although aspects of the work reflected each of the other types.

\section{Ethical Considerations}


Ethical approval for the study was obtained from the Local Research Ethics Committee. Procedures agreed included provision of written and verbal information about the study, an explanation that there was no obligation to take part, gaining consent of the participants and working to protect confidentiality. The lead investigator has worked through the study on a broad philosophy of 'ethical practices', in line with the framework detailed by Winter \& Munn-Giddings (2001, pp. 220-222), thereby considering each situation as it arises and trying to maintain the best interests of participants at all stages.

\section{Getting Started}

The study took place over a 2-year period and was coordinated by the action researcher (CK) who was the only funded member (18 hours per week) of the research team. Together, with a group of co-researchers from the newly formed stroke service and three members of the original stroke working party, they became known as the STEP team (Stroke Treatment for Every Person), reflecting the non-selective philosophy of the unit. The STEP team had representatives from nursing, medicine, occupational therapy, physiotherapy, speech and language therapy, and dietetics. The team had a core membership of six to eight people at anyone time, depending on staff changes due to people either leaving the Trust or gaining internal promotion. Other staff members from the stroke service joined the team along the way for time limited projects (see the action cycles below). The National Clinical Guidelines for Stroke (Intercollegiate Stroke Working Party [ISWP], 2000) were used as a foundation for instigating good practice. These guidelines had importantly been developed using the opinions and experience of stroke survivors and their carers (Kelson et al, 1998). Other user and carer involvement in the study included inclusion of a current carer and a previous service user, together with representatives from local and national stroke organisations on the multi-professional steering group that met quarterly to oversee the progress and direction of the project.

The study was strongly underpinned by the action research ethos of undertaking research with, for and by people, and operated within a structure of collaborative intent (Reason \& Bradbury, 2001). As such, all stroke service staff who wanted to be involved were supported and encouraged where possible to be drivers of their own service development. In reality, however, staff were often hard pressed for time in the clinical setting and so the main project responsibilities were primarily undertaken by the lead investigator, in keeping with the participatory nature of action research, in conjunction or consultation with the co-researchers wherever possible. These included:

- facilitating change;

- collecting and analysing data;

- feeding back the findings;

- reflecting on progress;

- coordinating multi-professional project groups;

- bridging the gap between clinicians and management;

- supporting co-researchers;

- administrating, organising meetings.

Prior to the start of the project, the action researcher had worked in the Trust for 5 years as a physiotherapist. During this time, she combined a clinical specialist role in neurological physiotherapy (including stroke) with a managerial role, and for the last three years she was the Head of the Physiotherapy Department. This prior experience gave access to insider knowledge and allowed the researcher to relate to colleagues with a high degree of clinical credibility (Gummesson, 2000; Coghlan \& Brannick, 2005). Nevertheless, adopting the role of an insider researcher in your own organisation is a complex process and requires the familiar to be looked at with a fresh perspective, coupled with an awareness not to assume any prior knowledge of answers (Coghlan \& Brannick, 2005). Furthermore, underlying assumptions require rigorous examination and reflection (Argyris et al, 1985). These aspects were addressed throughout the project by the regular feedback of findings to 
members of the STEP team and the wider stroke team and in reflective discussions with university supervisors (JM, MF, LP).

The notion of role duality, where the researcher is also trying to maintain a full organisational membership role, can bring conflict and ambiguity for both the action researcher and colleagues (Coghlan, 2003). In this study, the action researcher had to combine her clinical and managerial role, then augment that with the role of a researcher. Whilst the researcher's clinical credibility with staff in the stroke unit enabled her to affect change from the bottom up and her management experience allowed her to traverse organisational barriers with greater ease, it was not without personal cost as illustrated in the field notes 'I feel like I am sinking whilst juggling too many balls' (February 2002). She also sensed that some of her departmental colleagues were resentful of her protected time for research, as they made comments about her lack of visibility and support in the department, despite the managerial cover for her. Furthermore, at times she struggled to leave her physiotherapy role behind and become 'just a researcher' (March 2001) with access to a patient almost being denied by a relative when she realised that the physiotherapist was only seeing the patient to talk to their mother and not to 'do anything useful' (February 2002).

\section{Data Collection}

A variety of quantitative and qualitative methods were used to systematically generate data, and monitor the process and outcomes of change over time.

Before and after data were gathered from the National Sentinel Stroke Audit, a multidisciplinary audit tool developed by the Royal College of Physicians Intercollegiate Stroke Working party (Gompertz et al, 1994; Rudd et al, 2001). The audit looks at the organisation of stroke services and measures the clinical processes involved in 40 consecutive stroke patient admissions during a defined period. Members of the STEP team carried out local audits to supplement the national data (Mason et al, 2001; Mason \& Stone, 2001).

At the start of the study, focus groups facilitated by the action researcher and members of the STEP team, were carried out ( $n=7$ groups, total number of participants $=$ 51 ) to explore how staff wanted to implement and develop the stroke service. Various trust documents, policies and minutes from meetings were also gathered to further inform the context and background to the study. In-depth, semi-structured exploratory interviews carried out by the action researcher $(n=24)$ were used at the end of the study for staff to reflect on what had been achieved and learnt. Staff were also asked to complete a fivequestion survey, which was circulated to gather any outstanding staff views on the development of the stroke service. Throughout the study, reflective field notes of informal conversations and observations in the field were kept by the researcher ( 20 months). Issues arising from data collected were fed back to participants through weekly team meetings for verification, further exploration and action planning.

\section{The Action Research Cycles}

The need for improvement in stroke care had been identified as a problem by staff within the Trust and, hence, action research was purposively selected as the methodology of choice for this study. Through using a collaborative approach, action research looks to achieve an interventional change, whilst generating new knowledge from practice by studying the process and outcomes of change. By feeding back findings throughout the study, participants were able to influence the change process and have the opportunity to be actively engaged in the research.

Three action research cycles emerged from this study, in keeping with the philosophy of action research; they were not planned in advance and thus allowed the study to be participant led from findings in the field. 


\section{First Action Cycle: valuing and profiling stroke}

Definition of the Problem

Clinical staff recognised that stroke care was fragmented and marginalised within the many regional, national and international specialities in the trust.

\section{Work Carried Out by the STEP Team with Members of the Stroke Service}

This included:

- publicising the stroke unit by carrying out a wide consultation exercise with stakeholders (see Table II);

- having an official launch in conjunction with the Stroke Association;

- writing editorials for the British Medical Journal (Stone, 2002) and the International Journal of Therapy \& Rehabilitation (Kilbride, 2003);

- publishing articles in local press and hospital newsletters;

- contributing to a Department of Health publication on stroke services (DoH, 2001b);

- doing team and individual presentations locally and nationally;

- hosting a stroke conference and study days in the hospital;

- having a stand for Stroke Awareness week;

- organising a fundraising Charity Ball attended by over 200 people including stroke survivors.

Examples of people (stakeholders) consulted during the first action cycle included:

- users of the service, e.g. general practitioners, stroke patients and their carers, local resource centre used by stroke survivors;

- chief executive, trust board and senior managers within the trust;

- the trust's medical director, nurse director and head of therapy;

- commissioners of service (Primary care trust);

- Community Health Council;

- Royal College of Physicians;

- self-help groups, e.g. Stroke Association, Different Strokes, Connect and Pictures Speak;

- staff groups ranging from catering, Friends of the hospital, volunteer service, ward clerks, domestics in addition to nurses, therapists, social work, medics, etc.

\section{Second Action Cycle: building a team}

\section{Definition of the Problem}

The stroke unit was thought to have opened too quickly once the trust management had made the decision to do so. The sites selected for the ASU \& RSU were wards that were closed at the time due to financial constraints and so there was no foundation of collaboration upon which to build a stroke team.

\section{Work Carried Out by the STEP Team with Members of the Stroke Service} This included:

a. attending the Government's Modernisation Agency 'Clinical Governance Development Program (CGDP) for Stroke' [1];

b. facilitating multi professional project groups i.e. developing information resources for stroke, multidisciplinary documentation;

c. weekly 'time out' STEP meetings;

d. establishing team processes, i.e. goal planning, joint sessions, social activities.

The STEP team also successfully negotiated initially access and later membership of the Stroke Oversight Committee, which was set up by senior medical and management staff to oversee the implementation of medical input to the stroke service. The move to full multidisciplinary membership was facilitated by purposeful engagement of the STEP team with the Medical Director. 


\section{Third Action Cycle: sharing skills and knowledge}

Definition of the Problem

The staff in the stroke unit recognised that they lacked stroke specific skills and knowledge.

Work Carried Out by STEP Team with Members of the Stroke Service

This included:

- dysphagia training programme for nurses;

- establishing a multidisciplinary team education including seminars, workshops, study days;

- developing a computer-based stroke care pathway;

- defining core stroke competencies for Health Care Assistants;

- carrying out joint patient intervention sessions;

- goal setting;

- establishing staff rotational opportunities between the ASU and RSU.

\section{Data Analysis}

Thematic analysis of the qualitative data generated (semi-structured interviews, focus groups and reflexive field notes) were analysed using the process of Immersion/Crystallisation (I/C; see Figure 1), which is said to be suited to exploratory research where knowledge in the area is limited and to research that is participatory (Crabtree \& Miller, 1999). Borkan (1999) states that I/C 'cannot be reduced to a cookbook formula' (p. 180) and consists of 'cycles whereby the analyst immerses him- or herself into and experiences the text, emerging after concerned reflection with intuitive crystallisations, until reportable interpretations are reached' (Miller \& Crabtree, 1992).

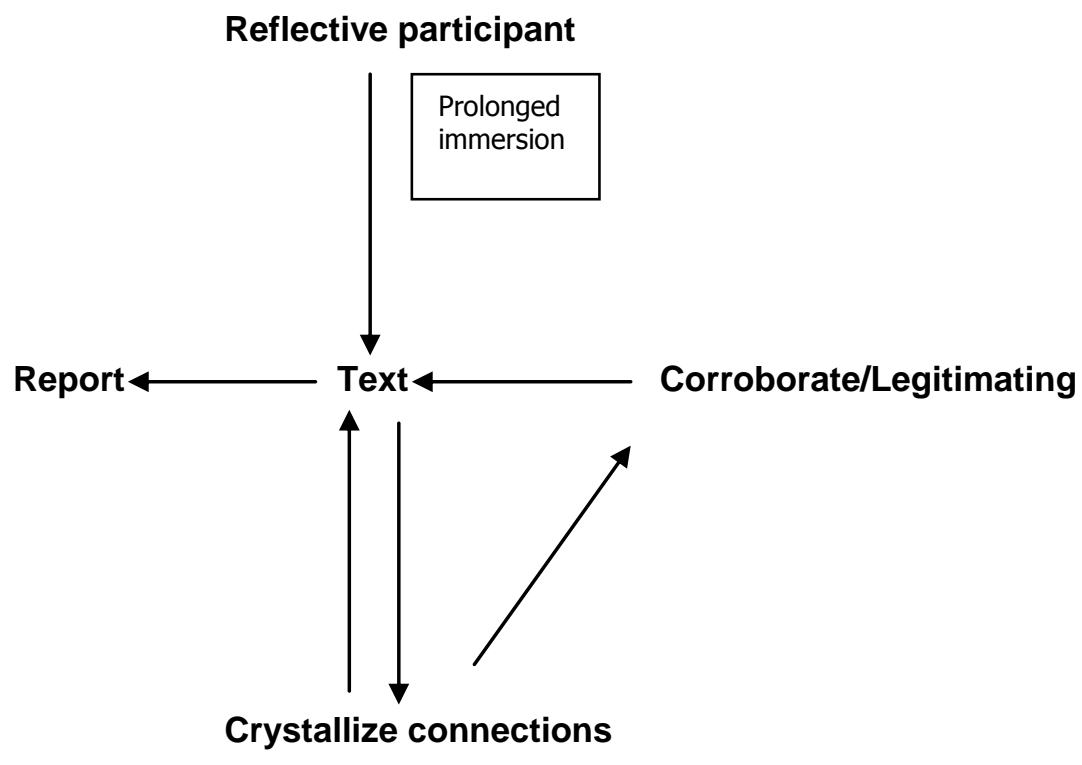

Fig. 1: The process of immersion and crystallization

(Adapted from Miller \& Crabtree 1992 p.18) 
The analysis was content driven from the data and reviewed using a technique of 'vertical passes' (Borkan, 1999, p. 186). This procedure consists of concentrating on one total data set at a time with prolonged review and analysis prior to moving on to another data set. In this project, the analysis passed vertically through data from the reflexive field notes, focus groups, semi-structured interviews and the descriptive survey, respectively. Efforts were made to assert validity of the findings through such aspects as reflexivity, depth of description, accuracy, rigour, intellectual honesty, and the searching for alternate hypotheses and interpretations (Borkan, 1999). The qualitative data were managed using the software package NVivo 1.3. Quantitative data were generated and extracted from local and national audits, and analysed using descriptive statistics. As stated previously, relevant trust policies and other documents were read and reflected on to illuminate the intentions behind setting up the Stroke Unit.

\section{Findings}

The findings are divided into two sections: positive changes over time and emerging process issues.

\section{Positive Changes Achieved over Time}

Overall, stroke care for patients within the Trust was markedly improved. For the first time there was a specialist stroke service for all, death rates fell from $24 \%$ in the first year to $15 \%$ two years later, higher scores were achieved on the national sentinel stroke audit and a Trust-based stroke prevention service was established. Some of the other positive outcomes are detailed in Table I.

\begin{tabular}{|l|l|}
\hline \multicolumn{1}{|c|}{ Pre-stroke unit } & \multicolumn{1}{c|}{ Post-stroke unit } \\
\hline Care for stroke fragmented over 18 wards & $\begin{array}{l}\text { Dedicated stroke service for all patients over 16 } \\
\text { years old based on two sites }\end{array}$ \\
\hline Death rate 24\% (Mason et al 2001) & Death rate fallen to 15\% (CEEu 2002) \\
\hline No specialist stroke staff in the hospital & $\begin{array}{l}\text { Dedicated multidisciplinary stroke team won } \\
\text { hospital team achievement award in 2000/01 for } \\
\text { their contribution to patient care. }\end{array}$ \\
\hline $\begin{array}{l}\text { Trust at bottom end of National Sentinel Stroke } \\
\text { Audit }\end{array}$ & $\begin{array}{l}\text { Stroke service in top 5\% of National Sentinel } \\
\text { Stroke Audit (CEEu 2002) }\end{array}$ \\
\hline $\begin{array}{l}\text { General rehabilitation only available for over 65s, } \\
\text { under 65s had to go out of district }\end{array}$ & Specialist stroke rehabilitation for all \\
\hline No stroke secondary prevention service & Weekly Trust stroke prevention clinic \\
\hline $\begin{array}{l}\text { Very limited education or support for patients and } \\
\text { carers }\end{array}$ & $\begin{array}{l}\text { Stroke coordinator in post. Local stroke booklet } \\
\text { printed, education programme set up patients } \\
\text { and carers }\end{array}$ \\
\hline Poor service user participation & $\begin{array}{l}\text { Increased patient participation through patient } \\
\text { group, feedback forms, key worker allocation }\end{array}$ \\
\hline No formal stroke education for staff & $\begin{array}{l}\text { Multidisciplinary team education established, } \\
\text { stroke study days for hospital, hosts annual } \\
\text { national stroke conference }\end{array}$ \\
\hline $\begin{array}{l}\text { No formal undergraduate training in stroke in the } \\
\text { trust }\end{array}$ & $\begin{array}{l}\text { Stroke service provides a training placement for } \\
\text { medical, nursing and therapy staff }\end{array}$ \\
\hline
\end{tabular}

Table I. Some of the changes in the Trust achieved over time.

\section{Emerging Process Issues}

The three coexisting action cycles of: valuing and profiling stroke; building a team and sharing skills and knowledge all contributed to the success of the new stroke service. However, in keeping with the philosophy of complexity theory, which is characterised by a combination of non-linear interactive components, unpredictability and emergent phenomena (Phelps \& Hase, 2002), it was not possible to isolate any one cause of improvement in stroke care. Nonetheless, through the in-depth study and systematic tracking of the process 
over time the project has enabled an understanding of how good stroke care can be implemented in practice. Moreover, implementation is rarely described in the literature, which can, in turn, lessen the understanding and learning of why an intervention is or is not locally successful (Bradley et al, 1999). Four interrelated factors strongly emerged from the data and seemed key to the outcome of successful stroke care. They are as follows:

- building a team (as a prerequisite for team working);

- developing practice-based knowledge and skills in stroke;

- valuing the central role of the nurse in stroke care;

- creating an organisational climate for supporting change.

The findings of this action research study related to teamwork and educational needs in stroke are generally supported in the literature (SUTC, 1997, 2004), but this study enhances the body of knowledge by providing additional depth and details by highlighting the need to build a team before trying to commence multidisciplinary teamwork. Whilst the need for specialisation of staff has been denoted in the National Clinical Guidelines for Stroke (ISWP, 2004) and the systematic review on in-patient stroke care (SUTC 1997, 2004), the findings of this study allude to the creation of a stroke specialism that, in turn, allows the nurse to claim a pivotal role in the multidisciplinary team. The final finding to emerge out of the process issues highlights a factor that is yet to gain prominence in the stroke literature, and this relates to the importance of engaging and maintaining widespread organisational support.

\section{Building a Team.}

Teamwork is the activity of people working cooperatively to achieve shared goals (Borrill et al, 2000). With increased specialisation it is unlikely that one health professional can meet all the complex needs of patients who are increasingly more complicated to manage (Hall \& Weaver, 2001). By working in a team, health professionals together can facilitate a wider variety of ways to ameliorate the multifaceted problems presented by many service users (Eva, 2002). Subsequent years have seen a continuing positive shift towards this more inclusive way of working in the UK National Health Service, with staff encouraged to think and work differently, breaking down artificial boundaries between professions to achieve staff working in genuine partnership (DH, 2000, 2002a,b. Yet it is important to recognise that health care teams are different from those in other types of organisations as team members have individual professional loyalties, as well as being a wider team member, and as such may have to deal with divided or conflicting allegiances (Firth-Cozens, 2001). Borrill et al (2000) suggests that the interest in team working in healthcare may reflect 'a deeper, perhaps unconscious, recognition that this way of working offers the promise of greater progress than can be achieved through individual endeavour' (p. 364). Increasingly, traditional professional boundaries are becoming less distinct, with roles being extended and developed (Bharji, 2003). Yet it needs to be acknowledged that role overlap is a complex issue and one that needs to be actively managed for optimum working relationships (Booth \& Hewison, 2002). However, just putting people together in an environment does not constitute a team or team working. West (2003) recommends that teams are given the opportunity to train to work together with appropriate tasks, but the experience for most healthcare teams is vastly different with limited time and opportunities for this in the workplace. Strong teamwork was a theme in the data and various participants remarked on it being a very different and positive way of working. It appeared that operational frameworks, such as multidisciplinary documentation and goal setting also strengthened the team approach:

I think it's a constant reminder that it is part of a team, and that you are part of a team, and that you're working towards joint goals, and that you are not on your own. (Therapist 2)

Change emerges over time and the road towards being part of a newly formed team can be challenging; acknowledgement and questioning of assumptions is an integral part of 
action research. The move towards becoming a stroke team can be viewed in complexity theory as introducing a 'noise', as it is a deliberate action that will promote a situation of disequilibria before attaining a new configuration (Phelps \& Hase, 2002). This is part of being a complex adaptive system, i.e. a collection of individual agents with freedom to act in ways that are not always totally predictable, and whose actions are interconnected so that one agent's actions changes the context for the other agents (Plsek \& Greenhalgh, 2001). Thus, different members or 'agents' of the team had to learn how to interact with each other. During the team-building phase the STEP team went through a period of 'disequilibria', as illustrated below in the quote taken from an interview:

It's (teamwork) something that is built up over time ... we were all trying to identify our roles ... trying our best to work together... we've done a good job on that eventually ... it was difficult in the beginning. I think some of the nurses were feeling that the therapists were taking over. (Therapist 4)

However, the situation was resolved itself, as with complexity theory, with the individual team members adapting and aligning with each other through a process of discussion and improved understanding of each other's roles (Lee, 1997). It is essential to have a clear understanding of professional boundaries, and reciprocal respect for the skills and abilities of other health care colleagues, to enhance professional working relationships (Brown \& Greenwood, 1999). Working in teams has also been demonstrated to positively affect mental health by cushioning individuals from the effects of organisational conflict (Borrill et al, 2000) and, importantly, allowing a sharing of responsibility amongst the team (Eva, 2002). More experienced team members can also be a valuable source of support for less experienced staff and so again help to reduce stress (Firth-Cozens, 2001). Furthermore, motivation is more likely to be maintained in a well functioning team (Eva, 2002). Ultimately, it is proposed that effective teams who demonstrate qualities such as trust, good communication, respect and strong leadership achieve improved patient outcomes (Sheridan, 2003). Systematic reviews by Langhorne \& Duncan (2001) and SUTC (2004) have shown this to be the case with stroke care.

Developing Practice-based Knowledge and Skills in Stroke.

Skills and knowledge are gained through working, learning, thinking and, importantly, doing. The attainment of knowledge crucially underpins clinical reasoning and decisionmaking, and thus is central to professional practice (Higgs \& Titchen, 2000). Attending to the experience is the first essential step in gaining knowledge through learning, followed by taking a step back to reflect and inquire (Coghlan \& Brannick, 2005). In action research the 'knowledge comes from doing' (Brydon-Miller et al, 2003, p. 14) and is developed through the dialectic process of creative conjecture and the test of experience (Winter \& MunnGiddings, 2001). Such accumulation of knowledge, both formally and informally, was felt to be a major key in the team delivering quality stroke care:

I think that l've learnt a huge amount in this year.

I think all the training that we've had and a lot more closer working together, l've learned an awful lot ... (Therapist 5)

It is like a family and you can talk to anyone. You learn from each other, which is excellent (Nurse 3)

Knowledge is gained through all aspects of working and, importantly, knowledge facilitates team participation; it gives you the rules of the game to take part. Knowledge without action is meaningless (Elden \& Chisholm, 1993, p. 122): 
The education programme so we understand more, makes the job more enjoyable, feels better because you know things (Nurse 8)

This gaining of knowledge was thought to have led to 'iterative cycles' of increased confidence in team members, which had a positive effect on competence and improved engagement between patients and staff, an amongst team members. Gibbon (1995) notes a correlation between knowledge and attitudes with the greater the nurse's understanding, the more positive the nurse is towards nursing involvement in rehabilitation. This, in itself, gave a higher capacity for experiential learning and, hence, the opportunity for more knowledge and this was seen in the STEP team (see Figure 2).

These informal learning opportunities may have been beneficial as it has been documented that adults learn best when the topic is of immediate value, is relevant and they are in a meaningful situation (Fraser \& Greenhalgh, 2001). Group learning within a team environment is also consistent with the participatory and collaborative aspect of action research, which is further supported by Sulivan Palincsar (1998) who suggested that social interaction and collaboration, together with individual cognitive processes, are essential to the creation of knowledge. Baldry Currens \& Bithell (2003) further support that peer interaction is useful as it was perceived to clarify individual thinking, challenge assumptions and support the construction of new knowledge.

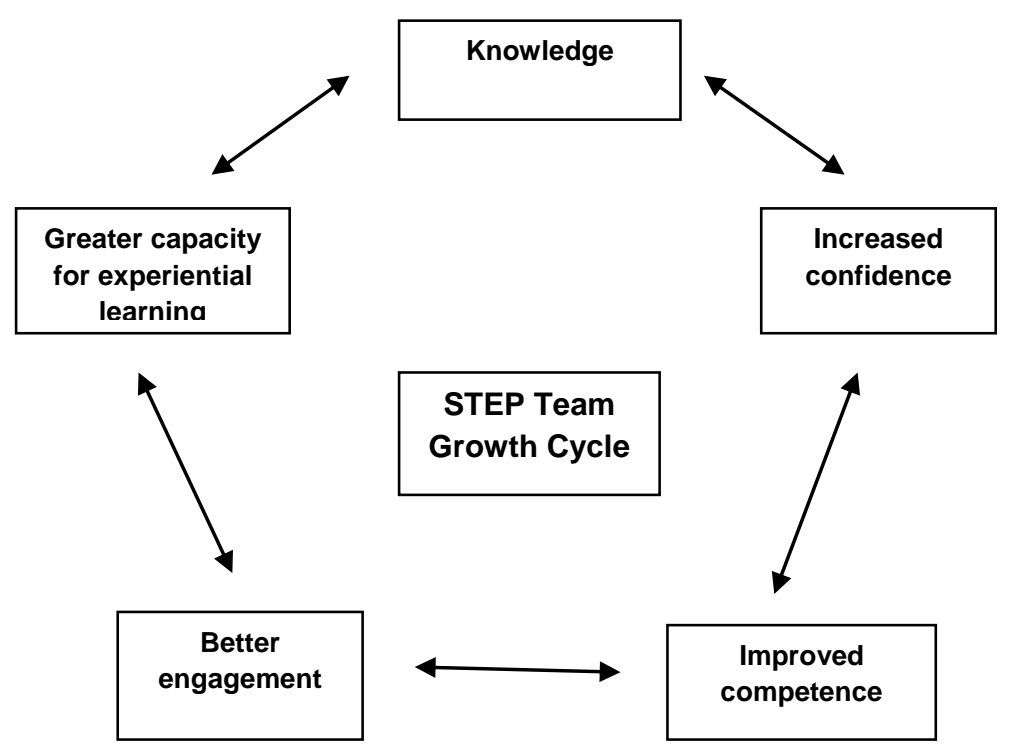

Figure 2. STEP Team Growth Cycle - the role of knowledge.

Valuing the Central Role of the Nurse in Stroke.

The contribution of nursing is hard to measure as many outcome measures are related to physical results, which emphasise the doing of the role, but fail to capture the wider holistic and complex nature of nursing (Spilsbury \& Meyer, 2001). O'Connor (1993) states that the nurse in rehabilitation tends to see the therapist as the expert and to see themselves as implementing the plans of therapists. Waters \& Luker (1996) reported that nursing staff felt rehabilitation was not inherent, but additional to their role and that they had difficulty elucidating their contribution in this area. However, in this study it was seen that in part, by creating a geographically defined stroke unit in which stroke patients were recognised as a speciality, it also importantly contributed to a sense of expertise for the nurses. This 'missing sense of expertise' within nursing was recently explored by Anstey 
(2003). This feeling of expertise was previously missing when the patients were spread throughout the hospital:

By having a stroke unit ... we like focusing on one condition, one thing stroke ... investing all our energies into that ... it builds expertise. (Nurse 5)

As nurses are the only professional group present 24-hours, 7 days a week, they are ideally positioned to be the hub for activity. In essence, they could act as the 'glue' for other health care professionals. Members of the multidisciplinary team have been found to be dependent on nursing colleagues to incorporate treatment plans into activities throughout the day, whilst also being able to provide feedback on progress (Long et al, 2002).

Furthermore, as acute stroke units are increasingly being established this has required the stroke nurse to take on additional key skills that include intensive monitoring with manipulation of physiological parameters and is in addition to the rehabilitation role that is more commonly associated with stroke (Hyde \& Dowell, 2002; Sulter et al, 2003).

However, in this study, due to the previous non-specialist nature of their work in relation to stroke, many of the nursing staff needed to develop specialist stroke skills in order to take up this more central role in the team. They had previously cared for stroke patients as part of their overall role as nurses in elderly care:

I think when the Stroke Unit opened first, we all thought that one stroke was like another stroke. But, you know, they've had a stroke, they're a stroke, but actually each patient has been an individual and we've learned an awful lot ... (Nurse 2)

I think we look more to their individual needs and what they can achieve, rather than before, when we used to do the caring, and we wouldn't have any plans or goals to achieve. We just nursed them to make them better. (Nurse 7)

The development of knowledge and practical skills was undertaken in a variety of ways including staff working with a specialist stroke coordinator (who was also a nurse), attending the MDT education seminars, and joint patient intervention sessions between nurses and therapists. For instance, the nurse would teach the therapist about areas such as catheter management or blood pressure. The therapist would then reciprocate by sharing on issues relating to positioning or mobility. In addition, specialist teaching on areas such as dysphagia management for nurses was arranged, thus extending the nursing role in the management of patient nutrition.

Another change is the staff and their professional stance ... they are confident \& competent. I can remember very well when I started that is was very difficult getting staff to talk to relatives. They would say they need to talk to the doctor, now they do it themselves. I feel this is as a result from the education seminars, which were a MDT approach. (Nurse 1)

Hickey \& Grotta (1999) state that the nurse assumes the major responsibility for education of patients and families as they spend the most time with the patients. Furthermore, nurses are also seen as key to providing emotional support for patients and families (Warner, 2000). Lincoln et al (1996) found that nurses on a specialist stroke unit were less likely to call upon a doctor in comparison to nurses in a general medical setting and were more likely to position patients correctly as they understood the importance of it, whereas on the other wards they did not correct postures even if they had time to. Likewise patients on the same stroke unit were found to spend less time lying down in comparison to patients on the 
general medical ward, thereby demonstrating a more active and specialist rehabilitation approach taken by the nurses on the stroke ward. This active role was mirrored in this project, with patients reporting (field notes) that nurses in the stroke service encouraged the patients to do more for themselves.

Overall, through a combination of increased skills and knowledge in stroke care and improved team working, the stroke unit nurses in this action research study began to claim a pivotal role in the team along with a distinct identity as specialist stroke nurses.

\section{Creating an Organisational Climate for Supporting Change.}

Achieving change in healthcare is a multifaceted process as the delivery of care is invariably implemented in large and complex systems across multiple organisational layers of occupational and professional groupings (Ferlie et al, 1999; Dopson et al, 2003).

Organisational learning, which draws upon the individual's knowledge to create 'a whole that is greater than the sum of the parts' (p. 262), is still only partially understood (Timpson, 1998). Nevertheless, it is recognised that through the process and implementation of change, mindsets and learnt behaviour are frequently challenged, and as a result requires continuous learning to take place (Timpson, 1998). This means that, although learning is generally undertaken and developed by individuals, organisational behaviour can either help or hinder the process, and has led to the term 'learning organisation' being adopted by those where learning features as a core characteristic (Davies \& Nutley, 2000).

Hence, as individuals and teams are inherently influenced by the organisational context in which they work, organisational support is crucial in the implementation of change (Borrill et al, 2000). Kitson et al (1998) undertook a theoretical and retrospective analysis of a number of case studies of change projects, and concluded that implementation was a product of the relationship between evidence, context and facilitation. Central to this association is a need for organisations to have an open and decentralised decision-making process as opposed to a dominant top-down directive stance (McCormack et al, 2002). The contextual setting where this action research project took place was a teaching hospital with a strong hierarchical structure, which had even been termed 'a fortress' by a senior person in the Trust during an exploratory interview (interview number 18). The collaborative approach of action research provided an excellent vehicle for the STEP team to build participation for change throughout the different layers of the organisation via a framework of inquiry, whilst also promoting learning from action. The widening of the membership of the stroke committee to include representation from the multidisciplinary team became a key factor in facilitating communication through the organisation. The combination of senior management and clinicians became an accomplished forum for influencing the strategic development of the service. A member of the STEP team now chairs this committee, which is only the second time in the Trust that a non-medical professional has held such a post.

As all members of the STEP team were insiders within the organisation, they had a prior understanding of the hospital and were able to utilise existing networks to facilitate engagement with key stakeholders in the Trust (Coghlan \& Brannick, 2005). However, networking often faltered at the highest level within the organisation. This was subsequently assisted by the STEP team's attendance at the stroke specific Clinical Governance Development Programme, a series of five seminars over a 9-month period, run by the UK's Government NHS Modernisation Agency. Formal agreement and support for the team's participation in the stroke programme had to be given by the Trust's Chief Executive and this effectively paved the way to access senior management views including that of the Chief Executive. Moreover, this gave the added strength of having internal management backing along with external support from the Government's Modernisation Agency. For the Trust itself, agreement and support for the Clinical Governance programme was seen as a positive move towards the goal of being a learning organisation. The team came to appreciate that they could exert greatest influence through the interplay of their individual and joint networks as the whole gave them a power greater than that of the sum of the individuals, thus reflecting an aspect of complexity theory. Furthermore, it is also worth noting that the team's attendance on the Stroke Clinical Governance programme not only provided positive 
organisational support, but it also gave the team valuable protected time out to practice working as a team. Most importantly, it created a 'space' for conversations and reflections (Treleaven, 2001, p. 263) to occur in their otherwise frenetic world of healthcare.

\section{Conclusion}

This in-depth case study looks inside the black box of stroke care because, although it has been established that stroke units work, it is not yet known what makes some stroke units more successful than others.

In this particular study, it was found that although it was not possible to highlight any one aspect that made a difference, there were four nonlinear interrelated main factors that arose from the action research cycles and were perceived to have contributed to the local success. They were:

- building a team;

- developing and sharing practice-based knowledge and skills in stroke;

- valuing the central role of the nurse in stroke care;

- creating an organisational climate for supporting change.

Whilst findings are generally supported by relevant literature where it is available, they do add depth to the body of knowledge and the findings related to widespread organisational engagement has not been explored in the stroke research literature.

It is said with non-linear systems that the reductionist approach, such as randomised controlled trials, will not provide the answers as the analysis of individual components belies the fact that it is the interaction between the parts that is important (Goldberger, 1996). Thus, the stroke service could be likened to a complex adaptive system (Plsek \& Greenhalgh, 2001; Phelps \& Hase, 2002), as it appears that success in this study seemed linked to the interplay of a range of factors. This is consistent with complexity theory, which explores how coherent and purposive wholes can emerge from the interactions of seemingly simple and sometimes even non purposive components (Lissack, 1999). Therefore, the concept of complexity, along with action research, both of which embrace the emergent nature of change and the role of agent interaction (Phelps \& Hase, 2002) provides an appropriate framework to further explore the holistic intervention for stroke.

This action research study is unique in describing how success was achieved in a newly established stroke unit; this may be relevant for others undertaking similar developments. Whilst it may be difficult to generalise findings to other contexts, it has been recognised that improvement in healthcare can be derived from undertaking formal evaluations of local projects, especially in relation to building theory around the complexity of change and the process of implementation (Harvey \& Wensing, 2003).

\section{References}

Anstey, K. (2003) The Nurse's Role in Promoting the Involvement of Older Patients and Informal Carers in the Assessment of their Individual Continuing Health and Social Care Needs. Unpublished PhD thesis, City University, London.

Argyris, C., Putnam, R. \& Smith, D. (Eds) (1985) Action Science. San Francisco: JosseyBass.

Baldry Currens, J. \& Bithell, C.P. (2003) The 2:1 Clinical Placement Model: perceptions of clinical educators and students, Physiotherapy, 89, pp. 204-218.

Bharji, K. (2003) Teamwork and the Code of Professional Conduct, Practising Midwife, 6, pp. 34-35.

Booth, J. \& Hewison, A. (2002) Role Overlap between Occupational Therapy and Physiotherapy during In-patient Stroke Rehabilitation: an exploratory study, Journal of Interprofessional Care, 16, pp. 31-40.

Borkan, J. (1999) Immersion/Crystallisation, in B. Crabtree \& W. Miller (Eds) Doing Qualitative Research. Thousand Oaks: Sage. 
Borrill, C., West, M., Shapiro, D. \& Rees, A. (2000) Team Working and Effectiveness in Health Care, British Journal of Health Care Management, 6, pp. 364-371.

Bradley, F., Wiles, R., Kinmouth, A-L., Mant, D. \& Gantley, M. (1999) Development and Evaluation of Complex Interventions in Health Services Research: case study of the Southampton heart integrated care project (SHIP), British Medical Journal, 318, pp. 711-715.

Brown, G.T. \& Greenwood, J. (1999) Occupational Therapy and Physiotherapy: similar but separate, British Journal of Occupational Therapy, 62, pp. 163-170.

Brydon-Miller, M., Greenwood, D. \& Maguire, P. (2003) Why Action Research? Action Research, 1, pp. 9-28.

Carr, W. \& Kemmis, S. (Eds)(1986) Becoming Critical: education, knowledge and action research. London: Falmer Press.

Clinical Effectiveness and Evaluation Unit (1998) National Sentinel Audit of Stroke 1998. Report for Site Code 175, prepared on behalf of the Intercollegiate Stroke Group by Clinical Effectiveness and Evaluation Unit: Royal College of Physicians, London.

Clinical Effectiveness and Evaluation Unit (1999) National Sentinel Audit of Stroke 1999. Report for Site Code 175, prepared on behalf of the Intercollegiate Stroke Group by Clinical Effectiveness and Evaluation Unit: Royal College of Physicians, London.

Clinical Effectiveness and Evaluation Unit (2002) National Sentinel Audit of Stroke 2001/2. Report for Site Code 175, prepared on behalf of the Intercollegiate Stroke Group by Clinical Effectiveness and Evaluation Unit: Royal College of Physicians, London.

Clinical Effectiveness and Evaluation Unit (2004) National Sentinel Audit of Stroke 2004. Organisation of Stroke Care, Report for Site Code 230, prepared on behalf of the Intercollegiate Stroke Group by Clinical Effectiveness and Evaluation Unit: Royal College of Physicians, London.

Coghlan, D. (2003).Insider Action Research Projects. Implications for Practising

Managers, Management Learning, 32, pp. 49-60.

Coghlan, D. \& Brannick, T. (Eds) (2005) Doing Action Research in Your Own Organization, 2nd edn. London: Sage Publications.

Crabtree, B. \& Miller, W. (Eds)(1999) Doing Qualitative Research. Thousand Oaks: Sage. Davies, H.T.O. \& Nutley, S.M. (2000) Developing Learning Organisations in the New NHS, British Medical Journal, 320, pp. 998-1001.

Department of Health (2000) The New NHS Plan. London: Stationery Office.

Department of Health (2001a) National Service Framework for Older People. London:

Stationery Office.

Department of Health (2001b) National Service Framework for Older People. What

Makes a Good Stroke Service and How Do We Get There? Available at:

http://www.doh.gov.uk/nsf/olderpeople.htm

Department of Health (2002a) Shifting the Balance of Power: the next steps. London:

Stationery Office.

Department of Health (2002b) Learning from Bristol: the DH Response to the report of the public inquiry into children's heart surgery at the Bristol Royal Infirmary 1984-1995. London. Stationery Office.

Dopson, S., Locock, L., Gabbay, J., Ferlie, E. \& Fitzgerald, L. (2003) Evidence-based Medicine and the Implementation Gap, Health, 7, pp. 311-330.

Ebrahim, S. \& Redfern, J. (1999) Stroke Care - a matter of chance. A National Survey of Stroke Services. London: Stroke Association.

Elden, M. \& Chisholm, R.F. (1993) Emerging Varieties of Action Research: introduction to the special issue, Human Relations, 46, pp. 121-142.

European Stroke Initiative Executive Committee and the EUSI Writing Committee (2003) European Stroke Initiative Recommendations for Stroke Management Update 2003, Cerebrovascular Diseases, 16, pp. 311-337. 
Eva, K.W. (2002) Teamwork during Education: the whole is not always greater than the sum of the parts, Medical Education, 36, pp. 314-316.

Ferlie. E., Wood, M. \& Fitzgerald, L. (1999) Some Limits to Evidence-based Medicine: a case study from elective orthopaedics, Quality in Health Care, 8, pp. 99-107.

Firth-Cozens, J. (2001) Multidisciplinary Teamwork: the good, bad, and everything in between, Quality and Safety in Health Care, 10, pp. 65-66.

Fraser, S.W. \& Greenhalgh, T. (2001) Coping with Complexity: educating for capability, British Medical Journal, 323, pp. 799-803.

Gibbon, B. (1995) Improving Stroke Care through Action Research, Journal of Clinical Nursing, 4, pp. 93-100.

Goldberger, A.L. (1996) Non-linear Dynamics for Clinicians: chaos theory, fractals, and complexity at the bedside, Lancet, 347, pp. 1312-1314.

Gompertz, P., Dennis, M., Hopkins, A. \& Ebrahim, S. (1994) Development and

Reliability of the Royal College of Physicians Stroke Audit Form, Age and Ageing,

23, pp. 378-383.

Gummesson, E. (Ed.) (2000) Qualitative Methods in Management Research, 2nd edn.

Thousand Oaks: Sage.

Hall, P. \& Weaver, L. (2001) Interdisciplinary Education and Teamwork: a long and winding road, Medical Education, 35, pp. 867-875.

Hankey, G.J. (1999) How Large a Public Health Problem, and How Can the Neurologist Help? Archives of Neurology, 56, pp. 748-754.

Hart, E. \& Bond, M. (Ed.) (1995) Action Research for Health and Social Care. a guide to practice. Buckingham: Open University Press.

Harvey, G. \& Wensing, M. (2003) Methods for Evaluation of Small Scale Quality Improvement Projects, Quality Safety in Health Care, 12, pp. 210-214.

Hickey, J.V. \& Grotta, J.C. (1999) What is the Role of Stroke Units in Overall Care? Disability Management Health Outcomes, 6, pp. 193-202.

Higgs, J. \& Tichen, A. (2000) Knowledge and Reasoning, in J. Higgs \& M. Jones (Eds)

Clinical Reasoning in the Health Professions, 2nd edn. Oxford: Butterworth Heinemann.

Hyde, S.L. \& Dowell, M.S. (2002) Acute Stroke Management: the importance of vital signs,

Nurse 2 Nurse, 2, pp. 10-12.

Indredavik, B., Bakke, F., Slordahl, S.A., Rokseth, R. \& Haheim, L.L. (1999)

Treatment in a Combined Acute and Rehabilitation Stroke Unit: which aspects are most important? Stroke, 30, pp. 917-923.

Intercollegiate Stroke Working Party (2000) National Clinical Guidelines for Stroke. London: Royal College of Physicians.

Intercollegiate Stroke Working Party (2004) National Clinical Guidelines for Stroke, $2^{\text {nd }}$ edn. London: Royal College of Physicians.

Kalra, L., Evans, A., Perez, I., Knapp, M., Donaldson, N. \& Swift, G. (2000) Alternative Strategies for Stroke Care: a prospective randomised controlled trial, Lancet, 356, pp. 894899.

Kelson, M., Ford, C. \& Rigge, M. (1998) Stroke Rehabilitation. Patient and Carer Views, a report by the College of Health for the Intercollegiate Working Party for Stroke.

London: Royal College of Physicians.

Kilbride, C. (2003) Stroke Treatment for Everyone: the team approach, International Journal of Therapy \& Rehabilitation, May 10, p. 5.

Kitson, A., Harvey, G. \& McCormack, B. (1998) Enabling the Implementation of Evidence-based Practice: a conceptual framework, Quality in Health Care, 7, pp. 149-158.

Langhorne, P. (1995) What is a Stroke Unit? A Survey of the Randomised Trials, Cerebrovascular Disease, 5, pp. 228-230.

Langhorne, P. \& Duncan, P. (2001) Does the Organization of Postacute Stroke Care Really Matter? Stroke, 32, pp. 268-274.

Langhorne, P. \& Pollock, A. in conjunction with the Stroke Trialists' Collaboration (2002) What are the Components of Effective Stroke Unit Care? Age and Ageing, 31 , pp. 365-371. 
Lee, M.E. (1997) From Enlightenment to Chaos: toward non-modern social theory, in R.A. Eve, S. Horsfall \& M.F. Lee (Eds) Chaos, Complexity and Sociology: myths, models and theories. Thousand Oaks: Sage.

Lincoln, N.B., Willis, B.A., Phillips, S.A., Juby, L.C. \& Berman, P. (1996) Comparison of Rehabilitation Practice on Hospital Wards for Stroke Patients, Stroke, 27, pp. 18-23. Lissack, M.R. (1999) Complexity: the science, its vocabulary and its relation to organizations. Available at: http://emergence.org/Complexity1.htm Long, A.F., Kneafsey, R., Ryan, J. \& Berry, J. (2002) The Role of the Nurse within the Multi-professional Rehabilitation Team, Journal of Advanced Nursing, 37, pp. 70-78. Mason, I. \& Stone, S.P. (2001) Re-audit of the Application of the Royal College of Physicians Guidelines on Drug Treatment of Acute Stroke. Unpublished, Royal

Free Hospital, London.

Mason, I., Stone, S.P. \& Kilbride, C. (2001) Retrospective Audit of 188 Patients Admitted to the Acute Stroke Unit. Unpublished, Royal Free Hospital, London

McCormack, B., Kitson, A., Harvey, G., Rycroft-Malone, J., Titchen, A. \& Seers, K. (2002) Getting Evidence into Practice: the meaning of 'context', Journal of Advanced Nursing, 38, pp. 94-104.

Meyer, J. (2000) Using Qualitative Methods in Health Related Action Research, British Medical Journal, 320, pp. 178-181.

Miller, W. \& Crabtree, B. (Eds) (1992) Doing Qualitative Research, in B. Crabtree \& W. Miller (Eds) Research Methods for Primary Care, vol. 3. Newbury Park: Sage.

O'Connor, S. (1993) Nursing and Rehabilitation: the interventions of nurses in stroke patient care, Journal of Clinical Nursing, 2, pp. 29-34.

Phelps, R. \& Hase, S. (2002) Complexity and Action Research: exploring theoretical and methodological connections, Educational Action Research, 10, pp. 507-523.

Plsek, P.E. \& Greenhalgh, T. (2001) The Challenge of Complexity in Health Care, British Medical Journal, 323, pp. 625-628.

Reason, P. \& Bradbury, H. (Eds) (2001) Handbook of Action Research. London: Sage. Rudd, A.G. \& Matchar, D.B. (2004) Health Policy and Outcome Research in Stroke, Stroke, 35, pp. 397-400.

Rudd, A.G., Irwin, P., Rutledge, Z., Lowe, D., Wade, D.T. \& Pearson, M. (2001)

Regional Variations in Stroke Care in England, Wales and Northern Ireland: results from the National Sentinel Audit of Stroke, Clinical Rehabilitation, 15, pp. 562-572.

Sheridan, M. (2003) Clinical Leadership. Part 2: transforming leadership, Professional Nurse, 18, pp. 716-717.

Spilsbury, K. \& Meyer, J. (2001) Defining the Nursing Contribution to Patient Outcome: lessons from a review of the literature examining nursing outcomes, skill mix and changing roles, Journal of Clinical Nursing, 10, pp. 3-14.

Stone, S.P. (2002) Stroke Units, British Medical Journal, 325, pp. 291-292.

Stroke Unit Trialists' Collaboration (1997) Collaborative Systematic Review of the Randomised Trials of Organised Inpatient (Stroke Unit) Care after Stroke, British Medical Journal, 314, pp. 1151-1159.

Stroke Unit Trialists' Collaboration (2004) Organised Inpatient (Stroke Unit) Care for Stroke (Cochrane Review), Cochrane Library Issue 3. Chichester: John Wiley \&Sons. Sulivan Palincsar, A. (1998) Social Constructivist Perspectives on Teaching and Learning, Annual Review of Psychology, 49, pp. 345-375.

Sulter, G., Elting, J.W., Langedijik, M., Maurits, N. \& De Keyser, J. (2003) Admitting Acute Ischemic Stroke Patients to a Stroke Care Monitoring Unit Versus a Conventional Stroke Unit: a randomized pilot study, Stroke, 34, pp. 101-104.

Timpson, J. (1998) The NHS as a Learning Organization: aspirations beyond the rainbow? Journal of Nursing Management, 6, pp. 261-272.

Treleaven, L. (2001) The Turn to Action and the Linguistic Turn: towards an integrated methodology, in P. Reason \& H. Bradbury (Eds) Handbook of Action Research. London: Sage. 
Warner, R. (2000) The Effectiveness of Nursing in Stroke Units, Nursing Standard, 14, pp. 32-35.

Waters, K.R. \& Luker, K.A. (1996) Staff Perspectives on the Role of the Nurse in Rehabilitation Wards for Elderly People, Journal of Clinical Nursing, 5, pp. 105-114.

West, M. (2003) Creating Effective Healthcare Teams, Frontline, 9, p. 16.

Winter, R. \& Munn-Giddings, C. (Eds)(2001) A Handbook for Action Research in Health and Social Care. London: Routledge.

World Health Organisation (1978) Cerebrovascular Disease: a clinical and research classification, Offset series No. 43. Geneva: WHO. 